\title{
Perspectives on Digital Content Markets: A Literature Review of Trends in Technologies, Business and Consumer Behaviour
}

\author{
Veikko Halttunen, Markus Makkonen, Lauri Frank, and Pasi Tyrväinen \\ Department of Computer Science and Information Systems, \\ University of Jyväskylä, Finland
}

\begin{abstract}
In this paper, we focus on digital content markets (DCMs), which have typically been seen as an offspring of technological and business innovations. However, recent trends indicate that these two perspectives are not enough when attempting to understand how DCMs actually work. Technology is obviously a prerequisite for business innovations, which in turn provide new possibilities for consumers. Nevertheless, consumer behaviour is not only a result of technological and business innovations, but by itself a crucial factor of DCMs. In this paper, we attempt to clarify the general view of DCMs by carrying out a literature study that is based on the above mentioned three perspectives: technology, business and consumer behaviour. As a result of our study, we present critical issues for both doing further research and improving the ways of trading and distributing digital content. Especially, we highlight the crucial role of societal transformations for the development of DCMS.
\end{abstract}

Keywords: digital content markets, technology, business, consumer behaviour

\section{Introduction}

The general view of digital content markets (DCMs) requires clarification. During the ongoing decade, digital content, such as documents, images, music and videos, has become an important source of new business (Stahl \& Maass 2006). However, companies that base their business on digital content have also faced the ill side of the trend, i.e. the severe problem of illegal copying and usage of digital products, also known as digital piracy (Haber et al. 2003). Digital piracy can be seen as a result of the easiness by which copying and sharing files on the Internet can be done (Frattolillo \& Landolfi 2008). The emergence of peer-to-peer (P2P) networks at the beginning of the millennium has led to the rapid development of illegal file sharing, especially in the area of music, and later on also in the area of videos (Einhorn \& Rosenblatt 2005).

Although the actual impacts of digital piracy on the content industries are

Copyright (C) 2010 Veikko Halttunen, Markus Makkonen, Lauri Frank and Pasi Tyrväinen.This is an open access article distributed under the Creative Commons Attribution License unported 3.0, which permits unrestricted use, distribution, and reproduction in any medium, provided that original work is properly cited. Contact Author: Veikko Halttunen, e-mail: veikko.halttunen@jyu.fi 
controversial (e.g. Oberholzer-Gee \& Strumpf 2007; Liebowitz 2008), it is obvious that piracy is an issue that requires much attention in the future. One way to fight against piracy are digital rights management (DRM) technologies, but so far their success in this has been quite limited (Jamkhedkar \& Heileman 2004). Nevertheless, DRM can be seen as a necessary addition to the arsenal of managing the distribution and usage of digital content. However, besides technologies, also other solutions are needed. These may include, for example, business models that better accommodate consumers' expectations (Amberg \& Schröder 2007). For this purpose, a better understanding of online consumers is required.

Consumers who utilise digital content over the Internet are typically young people. Their ways of thinking and acting can differ remarkably from those of earlier generations. There may be differences in ethical and moral values, social relationships and behaviour as well as in the ways of using different technologies. A more thorough understanding of online consumers is a prerequisite for digital content products and services that meet consumer expectations, and at the same time, form a basis for competitive and sustainable business. Social networking with its many applications (Facebook, MySpace, etc.) has already dramatically changed the ways in which communication technologies are utilised. It is obvious that in the future, virtual communities will have a significant role in consumers' everyday life (Constantinides \& Fountain 2008).

To analyse DCMs, we carried out a literature study that focused on several aspects of the market evolution. To systematise our data collection and analysis, we developed a simple model that describes three perspectives on DCMs and their interrelationships. The model is described in chapter 2 . In chapter 3 , we analyse each perspective of the model on the basis of our literature study. In chapter 4, we provide implications of the analysis on the model and on further research. In chapter 5 , we briefly summarise our study.

\section{Research model}

There is no doubt that technology has been one of the driving forces for the development of modern societies. Over the past twenty-thirty years, information and communication technologies (ICT) have heavily influenced individual and social behaviour, the ways of doing business, and the structures of societies. Thus, technology (ICT) is a main factor in our model (Figure 1).

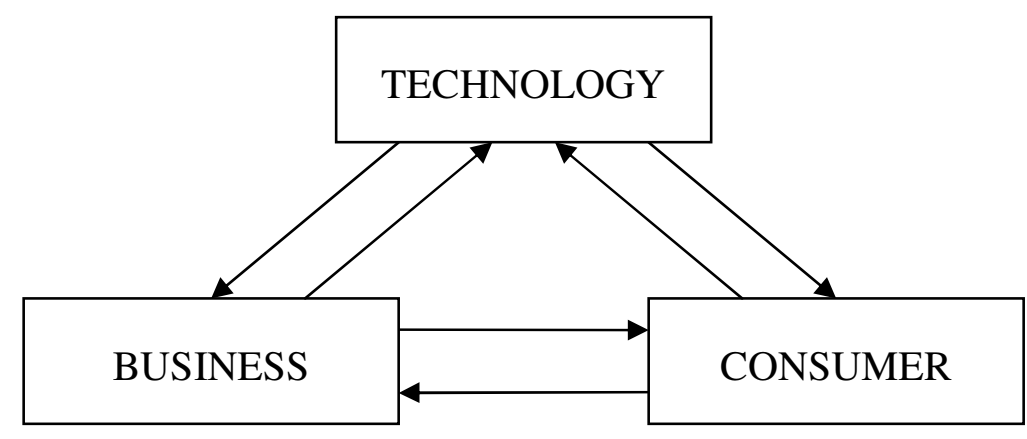

Fig 1. The original model 
Utilisation of technologies can be seen as a process through which individuals and organisations aim to use technologies in a beneficial way. When considering DCMs, the utilisation of technologies is realised in both business solutions and consumer behaviour. On one hand, business solutions and strategies are built taking the technological opportunities into account, resulting in innovative, technology-dependent or technologydriven business models. However, on the other hand, business innovations can be seen as an impetus for new technological innovations. Respectively, consumers utilise new technologies in a way that may change their behaviour. This, in turn, may entail new requirements for technological improvements.

In the remainder of the paper, the three components of our model are referred to as technology perspective, business perspective and consumer perspective. Since the model was developed to purely help to structure and analyse the overviewed literature, it must not be seen as exhaustive. However, we find that the high level of abstraction of the model makes it suitable to be utilised also more generally than just in this particular study.

\section{Analysis of digital content markets}

\section{Technological perspective}

Digital products, also referred to as digital content in this paper, are a natural result of the developments in personal computing and communication. According to Gartner (2008), the number of PCs exceeded one billion in June 2008, and this number is expected to double by 2014. The popularity of PCs has not only been guaranteed by their small size and low price, but also by the fact that with a modern PC, it is easy and efficient to consume and produce all types of content, such as text, images, audio and videos. As a result, a great variety of digital content is currently available to their users. In addition to PCs, there are nowadays various other devices available for listening to music or watching videos, such as portable media players (e.g. Apple iPod) and mobile phones with rich multimedia features (e.g. Nokia Nseries). Mobile devices have also quickly become an important means of accessing the Internet (ITU 2009).

From a communicational perspective, an important development step has been the emergence of efficient and inexpensive broadband access to the Internet. Although the early Internet technologies, such as IP (Internet Protocol), TCP (Transfer Control Protocol) and UDP (User Datagram Protocol), still form the technological core of the Internet, it was not until the emergence of WWW (World Wide Web) and its underlying technologies that the Internet became accessible to wider audience (Cantoni \& Tardini 2006). Later on, various improvements concerning the presentation of digital content have followed each other. The most important ones of these have been the common representation standards for audio (e.g. MP3, AAC and WMA), video (e.g. DivX, Xvid and WMV) as well as documents (e.g. $\mathrm{XML}$ and PDF). Whereas digital content typically has been acquired by downloading it as files, the increasing volume of audio and video content has also began to shift the focus onto streaming technologies, which enable the content to be used without having to download it entirely (Alustwani et al. 2008).

During this decade, a new innovative way to search and share digital content has emerged: P2P networks. These are networks whose architecture differs from the earlier client-server architecture in a way that all the network nodes are equal, i.e. each node can act both as a client and as a server. Thus, P2P networks are a typical example of distributed computing (Hawa 2008). The Napster file sharing 
service can be seen as an impetus for the numerous P2P networks that have emerged in this millennium (e.g. Taima 2002; Spitz \& Hunter 2005). Architecturally, P2P networks are complex and difficult to manage due to their heterogeneity and scalability problems (Kwong \& Tsang 2008). From the current P2P technologies, BitTorrent seems to have a prominent status (Hawa 2008).

Since digital content is nowadays conveniently accessible for a wide audience, the unauthorised copying and usage of content has proved to be a complicated problem. The technological solution to the problem has been the use of DRM, which may include the description, identification, trading, protection, monitoring and tracking of the rights over tangible or intangible assets in various electronic commerce systems (e.g. Ianella 2001; Tyrväinen 2005), using a variety of technical architectures and models (e.g. Liu et al. 2003; Ianella 2001). Over the years, several DRM products have been launched, but without considerable commercial success (Jamkhedkar \& Heileman 2004). This has mainly been due to their user experience and interoperability problems, immaturity of technologies, etc. DRM systems have also been seen as highly complex and extensive since they should be secure, flexible and manageable, and also provide a support for a diversity of devices, users, platforms and media (Michiels et al. 2005). Despite the adversity and failures of DRM products, new DRM innovations occur all the time (e.g. Sun et al. 2009; Lee 2009; Samtani 2009).

\section{Business perspective}

The first B2C digital content markets emerged in the mid-1990s around books, newspapers, journals, magazines and some small pieces of software, which were easily and efficiently distributable even over slow Internet connections.
However, as the speed of Internet connections increased, so did the size of products, and gradually the markets extended to cover more complex content products, such as games, music and films.

This emergence of DCMs and the transition from physical distribution to digital distribution has opened up many opportunities for the actors operating in the content industries. The most significant opportunity derives from the cost savings in distribution, of which Prekumar (2003) provides a good example from the music industry. Other opportunities include increased spatial and temporal freedom, faster deliveries, better service and wider selections, which are especially important from the consumer perspective. From the content creator perspective, the most important opportunity lays in the more direct and personal interaction with the consumers of their creations.

Besides opportunities, the emergence of DCMs also poses some serious threats to the actors operating in the content industries (Clemons et al. 2002). The most serious of these is probably digital piracy, which severely undermines the possibilities to operate profitable business based on digital content products. Another potential threat arises from the redistribution of bargaining power among the industry actors, which is driven by the recent transformations in the content industry value networks and business models.

A value network is a collection of upstream suppliers, downstream channels to market, and ancillary providers that support a common business model within an industry (Christensen 1997). The transition from physical distribution to digital distribution has initiated some radical transformations in the content industry value networks (Clemons et al. 2002; Graham et al. 2004; Bockstedt et al. 2006; 
Swatman et al. 2006). First, the value networks have gone through considerable disintermediation and reintermediation. Second, as the barriers to entry have become lower due to the new digital distribution channels, many specialist actors from other industries, such as Internet service providers and telephone companies, have started to enter the content industries. This has remarkably increased the volume and variety of actors available, and opened up opportunities for novel alliances and partnerships. Third, the new digital distribution channels have also severely undermined the dominant positions of the industry incumbents in the value networks and started to diffuse their bargaining power more equally among all the industry actors. Because all the distribution channels are no longer controlled by any single actor or group of actors, there are fewer opportunities for significant economies of scale or scope, which has opened up opportunities for the smaller actors, specialised in the niches of the "long tail" market (Anderson 2004), and decreased the incentives for vertical integration. All the actors have been forced to concentrate more and more on their own core competences and form strategic partnerships and alliances with other actors to support these activities, causing the value networks to become more complex, flexible and dynamic.

A business model is a representation of a company's underlying core logic and strategic choices for creating and capturing value within a value network (Shafer et al. 2005). Because a company's business model is always more or less customised for the value network in which the company operates, there is a strong interdependency between these two concepts. Therefore, not only the value networks, but also the business models of the companies operating in the content industries have gone through some significant transformations over the recent years. Because of this, great heterogeneity can be seen in the business models currently found in DCMs. To illustrate this heterogeneity, we will next present an overview of the best-known business models found in the online music markets, concentrating mainly on their pricing and revenue logic. Although the overview mainly concentrates on the online music markets, similar models can also be found in many other online content markets.

In the pay-per-transaction (or à la carte) model, users pay a separate fee for every song or album they download or listen. If the fee is charged for every download, the model is often referred to as the pay-perdownload model, and if the fee is charged for every listening, the model can be referred to as the pay-per-listen model. (Dubosson-Torbay et al. 2004) Pay-perlisten services are typically streaming based services to prevent users from storing the music for later use and listening to it free of charge. In pay-perdownload services, the music can usually be freely stored, but there may be some other restrictions, e.g. limiting the period of time a song can be listened to or the number of times it can be burned to a CD. (Amberg \& Schröder 2007) The bestknown example of pay-per-download services is Apple's iTunes Store.

In the subscription (or buffet) model, users pay a periodic flat fee and receive the right to download or listen to music either limitedly or unlimitedly for a certain period of time. Because the usage costs are more or less unrelated to the amount of usage, subscription services are especially attractive for so called "heavy users". However, compared to pay-pertransaction services, their success is much more dependent on the width of their music selection and the amount of additional services and information offered because a subscription typically for at least 30 days is a much bigger purchase barrier than a one-time 
transaction fee. (Amberg \& Schröder 2007) One of the best-known examples subscription services is RealNetworks's Rhapsody.

Many of the recently launched online music services are advertising supported services, which run entirely or at least partly on advertising revenues. Because of this, they are basically free of charge, but many of them also include some premium features, which are liable to charge. At the time, the two best-known advertising supported services are Last.fm and Spotify, although these both also include features from the pay-per-transaction and subscription models.

The redistribution model resembles the pay-per-download model in the sense that users pay a separate fee for every song or album they download. However, instead of just receiving the right to store and listen to the music, users also receive the right to resell it to other users. If they succeed in this, they are typically rewarded with a commission of the sales. The redistribution models have been studied quite actively over the recent years (e.g. Grimm \& Nützel 2002; Nützel \& Grimm 2003; Tyrväinen et al. 2004), but there are only few actual services utilising them (e.g. PotatoSystem).

\section{Consumer perspective}

The transition from non-digital products to digital products has changed both the attitudes and the behaviour of consumers. For instance, consumers have become more resistant to traditional forms of advertising, whereas alternative strategies, such as viral marketing, have gained ground (Leskovec et al. 2007). In viral marketing, existing social networks are utilised in sharing information about the products. Virtual communities on the Internet provide potential channels for this kind of word-of-mouth marketing.

Huang (2005) has studied consumer behaviour in the context of music file sharing. He noted that a new consumer subculture has emerged, which questions certain motivations and principles of traditional utilitarian behaviour. The production and consumption of digital content, a great proportion of which are hedonic and experience goods, are in many ways intertwined processes, which may require reconsidering the notion of a "pure" consumer.

Consumer ethics is a good example of the areas affected by the transition from traditional products to digital products. What is legal and what is illegal has become fuzzier to many consumers because illegal digital content is easy to find on the Internet, and many users both use and produce digital content. P2P networks and file sharing have provided consumers a convenient access to their favourite content, but at the same time, they have caused the severe problem of digital piracy (Cronan \& Al-Rafee 2007). In general, there seems to be quite a low level of guilt toward digital piracy (Chiang \& Assane 2007).

Soopramanien, Fildes and Robertson (2007) have found that consumers' willingness to shop online depends on the product in question. When consumers want to physically inspect the product before purchasing it, traditional purchasing channels are preferred. However, in the case of digital products, such as music and videos, also online purchasing channels are potential alternatives. In addition, Burkart (2008) suggests that in the case of music, consumers should be divided into two groups: ordinary music listeners and music fanatics. The latter group may still have good reasons for owning the physical products.

Since the Internet has become a potential alternative for consumers to acquire products and services, it would be interesting to know what are the actual motivators and barriers to online 
shopping. In a study by Chiang and Assane (2007), the main motivators for file sharing were costs, time and the access to content that was hard to find otherwise. In another study by Ahuja, Gupta and Raman (2003), convenience, time saving and better prices were found to be the most important motivators while security and privacy concerns seemed to be the biggest barriers. The barriers should be taken seriously since perceived risks play an important part in consumers' decisionmaking and behaviour, and consumers also tend to perceive higher levels of risk in online shopping compared to traditional shopping (Kunze \& Mai 2007).

Music is one of the most popular content types delivered over the Internet. A study by INDICARE (Dufft et al. 2005) polled the preferences of music consumers. It found that consumers prefer music files to be transferable between different devices as well as sharable with family and friends. In general, consumers seemed to dislike different kinds of restrictions in relation to music consumption. In regard to DRM, $55 \%$ of the respondents thought that DRM helps in compensating the artists, whereas $62 \%$ of the respondents thought that DRM only helps the music industry to increase their profits. Altogether, these findings can be interpreted in a way that consumers are more against DRM than for DRM, i.e. they see it serving the interests of the intermediaries instead of those of the artists and other content creators. Thus, it is not a surprise that some studies (e.g. Haber et al. 2003) suggest that DRM is not the sole solution to the severe problem of digital piracy.

\section{Implications}

This chapter is divided into two sections. In the first section, we consider our research model on the basis of the reviewed literature and rebuild the model. In the latter section, we provide a list of crucial issues for further studies.
Reconsideration of the model

In this section, we consider the linkages between the three components of our model and, as a result of the analysis, redraw our model.

Technology-Business. When considering DCMs from the technological perspective, P2P technologies seem to be the most challenging ones. They provide both outstanding opportunities and substantial threats. P2P networks are not just technological networks, but also social networks, which are part and parcel of peoples' everyday life. Whereas earlier online business models might have been technology-dependent or technologydriven, in new business models, consumers' ways of utilising the networks as well as their attitudes toward technologies should be more carefully taken into account. For example, when trying to deal with the piracy problems of P2P networks, DRM does not seem to be the right solution since most consumers are against any restrictive technologies. Thus, if technologies, such as DRM, are utilised, it must happen in a way that can be seen beneficial from consumers' point of view.

Online businesses will also face the convergence of information and communication technologies. Computer and mobile networks as well as television will most likely evolve to have a common base. This is a crucial factor when developing sustainable solutions for DCMs.

Technology-Consumer. For a consumer, the above mentioned P2P networks may appear as an unlimited and unrestricted resource. They will provide an easy and efficient way of proliferating digital content with few restrictions. As acquisition channels, they are often superior to other alternatives. It is wellknown that two factors are especially important when IT users form their attitudes toward technologies. These 
factors are the perceived ease of use, and perceived usefulness (Davis 1989). When both of these factors are in place, it is likely that the technology will be well received. Concerning the technologies reviewed in this paper, $\mathrm{P} 2 \mathrm{P}$ technologies seem to be widely accepted by consumers, while DRM is strongly resisted.

Business-Customer. From the analysis of the two linkages above, we can conclude that consumers' attitudes and behaviour should form the basis when developing new business models. Although this finding is not surprising, it must be remarked that previous business models seem to have been based more on efficient utilisation of technologies rather than on thorough understanding of consumers' expectations. New user generations of ICT are not plain users they are also active creators of the environment they use. Thus, in the future, it can be very difficult to make a clear distinction between creators and consumers of digital content. We believe that this phenomenon reflects wider changes in the societies. Thus, it deserves attention not only as part of business environment but also as part of the whole society.

Enhancing the model with 'Society'. Regarding DCMs, technologies, businesses and consumers form a complex whole that is in a continuous evolution. Changes in one component also affect the other two as described in the brief analysis above. In the context of building new information systems, technology and business aspects tend to have a dominant role. However, as Spitz and Hunter (2005) and Boczkowski (2004) point out, especially with the recent ICT innovations technological transformations should be considered as social processes. Without underestimating the importance of technological and business innovations, it must be remarked that all innovations take place in their societal context. With respect to new media this is even more important.

Technologies, businesses and consumers are all included in, and parts of the surrounding society. Like Spitz and Hunter (2005) note in their analysis of Napster, technologies do not spring from void, but they must have a favourable cultural ground. The values and practices of the members of a society have a crucial role in the adoption of new innovations (Rogers 2003). For example, Wikipedia is a well-known, free-to-anyone application that is widely used by a large number of people. Hansen et al. (2009) have defined Wikipedia as an emancipatory system. One could argue that the success of Wikipedia just originates from the emancipatory tendencies in modern societies.

Society is not only a fruitful ground for new innovations. It is also a pivotal factor in preventing the unwanted consequences of new technological and business innovations. Different parties have different motives and aims. All of them should be considered at the level of the whole society. Regarding current DCMs, digital piracy seems to be the major problem. The problem reflects inconsistencies in the values and actions of the different actors. Since unilateral measures like restrictive legislation or technologies cannot alone resolve the problem, there is a need for a comprehensive societal planning of the future. An in-depth understanding of all the important factors of DCMs is necessary.

Highlighting the crucial role of societal development, we redraw our model as depicted in Figure 2. 


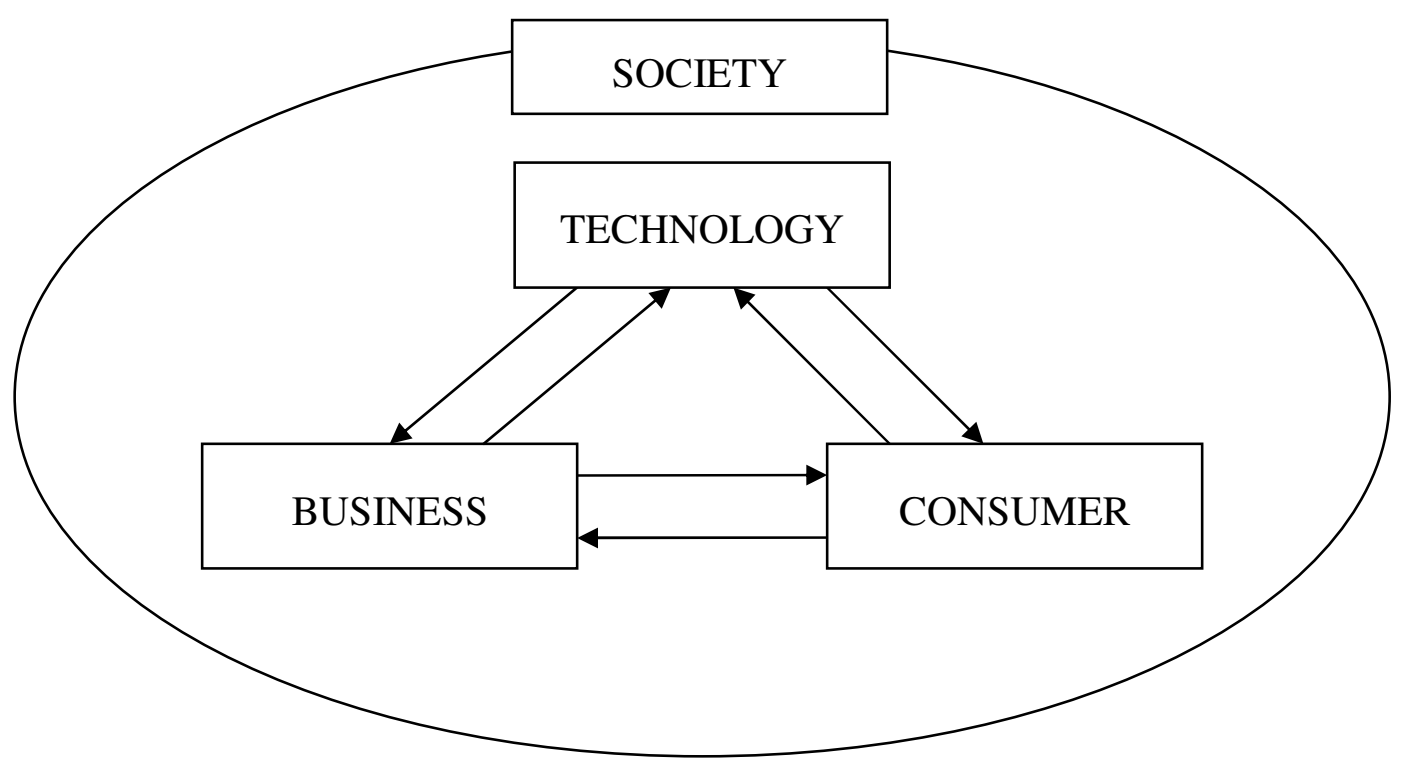

Fig 2. The redrawn model

\section{Implications for further studies}

As already discussed in this paper, online businesses based on digital content, such as music and videos, face several problems that are not relevant to traditional business - not even to online business based on traditional goods. The main problem of digital content is the easiness of consuming it illegally. In a short term, this can be seen as a problem of content providers, but in a longer term, the question is more general by nature: Who actually pays for the content, and who will care about creating and producing high quality content, if the creators and producers of the content are not fairly compensated?

Actually, the problem is not only about the illegal copying and usage of digital content, i.e. digital piracy, but it is also about the changes in consumer behaviour, and furthermore, about the overall changes in society. For older generations, the Internet is either a distant thing or a useful tool for getting information or getting some everyday tasks done, whereas for younger generations it is a means to make friends, communicate and share experiences, and as part of this, also to share digital contents. We have already discussed how a simple moral question, what is right and what is wrong, may be responded differently by different generations. Thus, also the problem of digital piracy may be seen differently by people of different ages. When trying to predict the future, we must above all concentrate on the younger generations since their ways of thinking and acting are pivotal when building new sustainable solutions for both businesses and the societies.

In our literature survey, we found that most of the studies on DCMs have so far been positioned in the technology and business domains of our model, and therefore future studies should concentrate more on actual consumer behaviour and its interdependencies with 
technological and business issues. These issues can be summarised as follows:

First, since the younger generations will be the "heavy users" of digital content in the future, what are their attitudes toward digital content as a product? What do they think about online services and distribution channels, how willing are they to pay for the products, what would they consider a fair compensation mechanism and how effective would different business models and marketing mixes prove to be? Furthermore, how do different consumer segments (e.g. ordinary music listeners vs. music fanatics) differ from each other in relation to their motivations and behaviour, and is there any variation in these issues between different content categories (e.g. music and videos)? Who are the opinion leaders when it comes to digital content?

Second, if consumers are not willing to pay for digital content, what are the reasons for this? Are the products not providing them with enough benefits and value, or is there something wrong in their pricing? Or are there perhaps other barriers, such as privacy concerns (e.g. misuse of private information) or security concerns (e.g. security of payment systems), that might influence their behaviour? What could be done to solve these issues? Moreover, if consumers are not willing to pay for digital content at all, how should their production be organised? Should we resort on market mechanisms, or on alternate solutions such as Internet or ISP levies already suggested in New Zealand (NZ Herald 2008) and Canada (CBC.ca 2009).

Third, since there are many different technologies, devices and distribution channels available (e.g. the Internet, television, mobile phones and other mobile devices), what pros and cons do consumers perceive in each technology, and in which contexts do consumers prefer each technology? Are there differences between consumers in relation to these perceptions and preferences? What are the implications of technological convergence to all this?

\section{Summary}

We summarise our study as follows. First, the technological solutions that have enabled the new online business based on the distribution of digital content have also enabled the illegal copying and usage of that content in a way that is difficult or even impossible to deal with purely technological or legislative means, such as DRM or copyright laws. In future business models, new online consumer subcultures should more carefully be taken into account. These subcultures, which are heavily based on social networking and virtual communities, have a strong impact on the ways consumers both think and act. It is not a surprise that DRM, for example, has raised strong resistance among consumers. DRM, which basically aims at limiting the illegal copying and usage of copyright protected content, has little chances to be successful if consumers consider it just as another restriction that lowers the value of the content.

In brief, consumer expectations and their ways of thinking and acting as well as societal changes throughout the society should be understood more thoroughly. This understanding should form the basis for building successful and sustainable solutions for digital content distribution. Since the intentions to behave in a certain way in certain situations are an appropriate surrogate for the actual consumer behaviour, further studies could focus on building consumer behaviour models that, on one hand, utilise the previously proven theories and models, but on the other hand, take the specific features of online consumption and digital content into account. In addition, there is a need to study further the actual consumer behaviour itself. In this way, it is possible to gather 
information that could be used to improve the applicability and accuracy of the before mentioned intention-based models.

\section{References}

Ahuja, M., Gupta, B., and Raman, P. (2003) "An Empirical Investigation of Online Consumer Purchasing Behavior," Communications of the ACM (46:12), pp. 145-151.

Alustwani, H., Bahi, J. M., and Mostefaoui, A. (2008) "Data Availability in P2P Streaming Systems," in Proceedings of the Second International Conference on Next Generation Mobile Applications, Services, and Technologies (NGMAST 2008), K. AlBegain, and A. Cuevas Casado (eds.), IEEE Computer Society, Los Alamitos, CA, pp. 531-536.

Amberg, M., and Schröder, M. (2007) "Ebusiness models and consumer expectations for digital audio distribution," Journal of Enterprise Information Management (20:3), pp. 291303.

Anderson, C. (2004) "The Long Tail," Wired (12:10), 2004, pp. 170-177.

Bockstedt, J. C., Kauffman, R. J., and Riggins, F. J. (2006) "The Move to ArtistLed On-Line Music Distribution: A Theory-Based Assessment and Prospects for Structural Changes in the Digital Music Market," International Journal of Electronic Commerce (10:3), pp. 7-38.

Boczkowski , P. J. (2004), "The Mutual Shaping of Technology and Society in Videotex Newspapers: Beyond the Diffusion and Social Shaping Perspectives," The Information Society, 20, pp. 255-267.

Burkart, P. (2008) "Trends in Digital Music Archiving," The Information Society (24:4), pp. 246-250.
Cantoni, L., and Tardini, S. (2006) Internet, Routledge, London, England.

CBC.ca. (2009) Internet providers united in opposing CRTC regulation, 2009. Retrieved from http://www.cbc.ca/technology/story/20 09/03/11/isp-newmedia.html

Chiang, E. P., and Assane, D. (2007) "Determinants of music copyright violations on the university campus," Journal of Cultural Economics (31:3), pp. 187-204.

Christensen, C. M. (1997) The Innovator's Dilemma: When New Technologies Cause Great Firms to Fail, Harvard Business School Press, Cambridge, MA, 1997.

Clemons, E. K., Gu, B., and Lang, K. R. (2002) "Newly Vulnerable Markets in an Age of Pure Information Products: An Analysis of Online Music and Online News," Journal of Management Information Systems (19:3), pp. 17-41.

Constantinides, E., and Fountain, S. J. (2008) "Web 2.0: Conceptual foundations and marketing issues," Journal of Direct, Data and Digital Marketing Practice (9:3), pp. 231-244.

Cronan, T. P., and Al-Rafee, S. (2007) "Factors that Influence the Intention to Pirate Software and Media," Journal of Business Ethics (78:4), 2007, pp. 527-545.

Davis, F. D. (1989) "Perceived Usefulness, Perceived Ease of Use, and User Acceptance of Information Technology," MIS Quarterly (13:3), pp. 319-340.

Dubosson-Torbay, M., Pigneur, Y., and Usunier, J.-C. (2004) "Business Models for Music Distribution after the P2P Revolution," in Proceedings of the Fourth International Conference on Web Delivering of Music (WEDELMUSIC 2004), J. Delago, P. Nesi, and K. Ng (eds.), IEEE 
Computer Society, Los Alamitos, CA, pp. 172-179.

Dufft, N., Stiehler, A., Vogeley, D., and Wichmann, T. (2005) Digital Music Usage and DRM: Results from a European Consumer Survey, INDICARE Consumer Surveys, 2005. Retrieved from http://www.indicare.org/tiki-

download file.php?fileId $=110$

Einhorn, M. A., and Rosenblatt, B. (2005) Peer-to-Peer Networking and Digital Rights Management: How Market Tools Can Solve Copyrights Problems, Cato Institute Policy Analysis No. 534. Retrieved from: http://www.cato.org/pub display.php?pu $\underline{\mathrm{b} \text { id }=3670}$

Frattolillo, F., and Landolfi, F. (2008) "Designing a DRM System," in Proceedings of the Fourth International Symposium on Information Assurance and Security (IAS 2008), M. Rak, A. Abraham, and V. Casola (eds.), IEEE Computer Society, Los Alamitos, CA, pp. 221-226.

Gartner. (2008) Gartner Says More than 1 Billion PCs In Use Worldwide and Headed to 2 Billion Units by 2014. Retrieved from www.gartner.cpm/it/page.jsp?id=703807

Graham, G., Burnes, B., Lewis, G. J., and Langer, J.(2004) "The transformation of the music industry supply chain: A major label perspective," International Journal of Operations \& Production Management (24:11), pp. 1087-1103.

Grimm, R., and Nützel, J. (2002) "Peer-toPeer Music-Sharing with Profit but Without Copy Protection," in Proceedings of the Second International Conference on Web Delivering of Music (WEDELMUSIC 2002), C. Busch, M. Arnold, P. Nesi, and M. Schmucker (eds.), IEEE Computer Society, Los Alamitos, CA, pp. 17-22.

Haber, S., Horne, B., Pato, J., Sander, T., and Tarjan, R. E. (2003) "If Piracy is the
Problem, Is DRM the Answer?" in Digital Rights Management: Technological, Economic, Legal and Political Aspects, E. Becker, W. Buhse, D. Günnewig, and N. Rump (eds.), Springer, Heidelberg, Germany, pp. 224-233.

Hansen, S., Berente, N., and Lyytinen, K. (2009) "Wikipedia, Critical Social Theory, and the Possibility of Rational Discourse," The Information Society, 25, pp. 38-59.

Hawa, M. (2008) "A Measurement Study of Shared Content on Peer-to-Peer Networks," in Proceedings of the 2008 International Symposium on Performance Evaluation of Computer and Telecommunication Systems (SPECTS 2008), M. S. Obaidat, J. L. Marzo, H. Szczerbicka, and P. Vila (eds.), IEEE Communications Society, New York, NY, pp. 277-284.

Huang, C.-Y. (2005) "File Sharing as a Form of Music Consumption," International Journal of Electronic Commerce (9:4), pp. 37-55.

Iannella, R. (2001) "Digital Rights Management (DRM) Architectures," D-Lib Magazine (7:6). Retrieved from: http://www.dlib.org/dlib/june01/iannell a/06iannella.html

ITU. (2009) Measuring the Information Society - The ICT Development Index, ITU Telecommunication/ICT Indicators Reports, 2009. Retrieved from http://www.itu.int/ITU-

D/ict/publications/idi/2009/index.html

Jamkhedkar, P. A., and Heileman, G. L. (2004) "DRM as a Layered System," in Proceedings of the Fourth ACM Workshop on Digital Rights Management (DRM'04), A. Kiayias, and M. Yung (eds.), ACM, New York, NY, pp. 11-21.

Kunze, O., and Mai, L.-W. (2007) "Consumer adoption of online music services: The influence of perceived risks 
and risk-relief strategies," International Journal of Retail \& Distribution Management (35:11), pp. 862-877.

Kwong, K.-W., and Tsang, D. H. K. (2008) "Building Heterogeneous Peer-to-Peer Networks: Protocol and Analysis," IEEE/ACM Transactions on Networking (16:2), pp. 281-292.

Lee, J. (2009) "P2P Based Private Broadcasting DRM System," The $11^{\text {th }}$ International Conference on Advanced Communication Technology (ICACT 2009), Phoenix Park, Korea.

Leskovec, J., Adamic, L. A., and Huberman, B. A. (2007) "The Dynamics of Viral Marketing," ACM Transactions on the Web (1:1), pp. 1-39.

Liebowitz, S. J. (2008) "Research Note: Testing File Sharing's Impact on Music Album Sales in Cities," Management Science (54:4), pp. 852-859.

Liu, Q., Safavi-Naini, R., and Sheppard, N. P. (2003) "Digital Rights Management for Content Distribution," in Proceedings of the First Australasian Information Security Workshop (AISW 2003), C. Johnson, P. Montague, and C. Steketee (eds.), ACM, New York, NY, pp. 49-58.

Michiels, S., Verslype, K., Joosen, W., and De Decker, B. (2005) "Towards a Software Architecture for DRM," in Proceedings of the Fifth ACM Workshop on Digital Rights Management (DRM'05), R. Safavi-Naini, and M. Yung (eds.), ACM, New York, NY, pp. 65-74.

Nützel, J., and Grimm, R. (2003) "Potato System and Signed Media Format - an Alternative Approach to Online Music Business," in Proceedings of the Third International Conference on Web Delivering of Music (WEDELMUSIC 2003), K. Ng, C. Busch, and P. Nesi (eds.), IEEE Computer Society, Los Alamitos, CA, pp. 23-26.
NZ Herald. (2008) Fee plan to combat net piracy, 2008. Retrieved from http://www.nzherald.co.nz/internet/new s/article.cfm?c id=137\&objectid=105235 $\underline{35}$

Oberholzer-Gee, F., and Strumpf, K. (2007) "The Effect of File Sharing on Record Sales: An Empirical Analysis," Journal of Political Economy (115:1), pp. 1-42.

Prekumar, G. P. (2003) "Alternate distribution strategies for digital music," Communications of the ACM (46:9), pp. 89-95.

Rogers, E. M. (2003) Diffusion of Innovations ( $5^{\text {th }}$ ed.). New York, NY: Free Press.

Samtani, R. (2009) "Ongoing Innovation in Digital Watermarking," Computer (42:3), pp. 92-94.

Shafer, S. M., Smith, H. J., and Linder, J. C. (2005) "The power of business models," Business Horizons (48:3), pp. 199-207.

Soopramanien, D. G. R., Fildes, R., and Robertson, A. (2007) "Consumer decision making, E-commerce and perceived risks," Applied Economics (39:17), pp. 2159-2166.

Spitz, D., and Hunter, S. D. (2005) "Contested Codes: The Social Construction of Napster," The Information Society (21:3), pp. 169-180.

Stahl, F., and Maass, W. (2006) "Adoption and Diffusion in Electronic Markets: An Empirical Analysis of Attributes Influencing the Adoption of Paid Content," Electronic Markets (16:3), pp. 233-244. 
Sun, M.-K., Laih, C.-S., Yen, H.-Y., and Kuo, J.-R. (2009) "A Ticket Based Digital Rights Management Model," The $6^{\text {th }}$ IEEE Consumer Communications and Networking Conference (CCNC 2009), Las Vegas, NV.

Swatman, P. M. C., Kruger, C., and van der Beek, K. (2006) "The changing digital content landscape: An evaluation of ebusiness model development in European online news and music," Internet Research (16:1), pp. 53-80.

Taima K. (2002) "Can We Ever Charge Napster Users?" IEEE MultiMedia (9:4), pp. 76-81.

Tyrväinen, P. (2005) "Concepts and a Design for Fair Use and Privacy in DRM," D-Lib Magazine (11:2). Retrieved from: http://www.dlib.org/dlib/february05/tyr vainen/02tyrvainen.html

Tyrväinen, P., Järvi, J., and Luoma, E. (2004) "Peer-to-Peer Marketing for Content Products - Combining Digital Rights Management and Multilevel Marketing," The IADIS International Conference on e-Commerce 2004 (EC 2004), Lisbon, Portugal. 